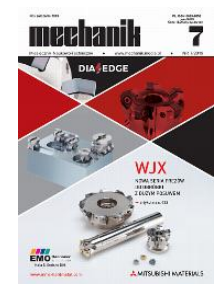

How to cite this article:

Authors: Paweł Bałon, Andrzej Świątoniowski, Edward Rejman, Bartłomiej Kiełbasa, Robert Smusz, Janusz Szostak,

Łukasz Kowalski

Title of article: „Springback phenomenon of vehicle's bumper in cold and hot forming methods”

Mechanik, No. 7 (2019)

DOI: https://doi.org/10.17814/mechanik.2019.7.48

\title{
Springback phenomenon of vehicle's bumper in cold and hot forming methods
}

\author{
PAWEL BALON \\ ANDRZEJ ŚWIĄTONIOWSKI \\ EDWARD REJMAN \\ BARTŁOMIEJ KIEŁBASA \\ ROBERT SMUSZ \\ JANUSZ SZOSTAK \\ ŁUKASZ KOWALSKI *
}

\begin{abstract}
Dr inż. Paweł Bałon, p.balon@szel-tech.pl, https://orcid.org/0000-0003-3136-7908 - SZEL-TECH Szeliga Grzegorz, Mielec, Polska; Akademia Górniczo-Hutnicza w Krakowie, Kraków, Polska

Prof. dr hab. inż. Andrzej Świątoniowski, swiatoni@imir.agh.edu.pl, https://orcid.org/0000-0003-4832-3418 - Akademia Górniczo-Hutnicza w Krakowie, Kraków, Polska

Dr inż. Edward Rejman, erejman@prz.edu.pl, https://orcid.org/0000-0003-4716-7613 - Politechnika Rzeszowska im. Ignacego Łukasiewicza, Rzeszów, Polska

Mgr inż. Bartłomiej Kiełbasa, b.kielbasa@szel-tech.pl, https://orcid.org/0000-0002-3116-2251 - SZEL-TECH Szeliga Grzegorz, Mielec, Polska Dr inż. Robert Smusz, robsmusz@prz.edu.pl, https://orcid.org/0000-0001-7369-1162 - Politechnika Rzeszowska im. Ignacego Łukasiewicza, Rzeszów, Polska

Dr inż. Janusz Szostak, szostak@agh.edu.pl, https://orcid.org/0000-0002-7789-3383 - Akademia Górniczo-Hutnicza w Krakowie, Kraków, Polska Mgr inż. Łukasz Kowalski, lkowalski@agh.edu.pl, https://orcid.org/0000-0002-2866-9000 - Akademia Górniczo-Hutnicza w Krakowie, Kraków, Polska
\end{abstract}

In order to meet the increasing requirements introduced by European Union directives and guidelines for the automotive industry, in the area of increasing safety while constantly reducing carbon dioxide emission limits, companies in the automotive industry implement new materials and new technologies for production. Currently, two trends are propagated in the way of manufacturing car body elements: the cold forming process of steel with a tensile strength $R_{\mathrm{m}}$ up to $1600 \mathrm{MPa}$ and the hot forming process of steel with a strength $R_{\mathrm{m}}$ of up to $1800 \div 2000 \mathrm{MPa}$. The largest European manufacturers of car parts must meet the design and manufacture of hot forming tools. It is one of the most modern pressing technologies implemented for several years in innovative plants located both in Europe and the USA. Designing and testing of this type of tools are carried out by companies with advanced technological production capabilities. The use of this type of technology increases the level of product innovation, due to the know-how of companies for such complex tools, despite the fact that the costs of tools significantly exceed the costs of standard dies. The competition on the European market in the production of parts in hot forming process is not so large at the moment.

KEYWORDS: springback, hot forming, cold forming, UHSS

\section{Introduction}

Cold forming technology involves pressing steel at a temperature below the recrystallization temperature. To ensure adequate load bearing capacity of key car structural elements exposed to high loads (e.g. bumper beams), they are made of materials of adequate strength, such as HCT780X steel with a strength limit $R_{\mathrm{m}}$ above $780 \mathrm{MPa}$ (fig. 1).

The use of high-strength steel increases the intensity of the springback effect. The problem arises both during the machining and inspection of these elements, and during the assembly of molded parts into subassemblies. Maintaining small tolerances for elements made of HSS (high strength steel) or advanced high strength steel (AHSS) is difficult, especially when the material has a tendency to elastic deformation during cutting or unloading after forming.

Springback is a process of flexible return with a local plastic deformation, manifested at the end of the process. In the case of multi-operative tools, springback also occurs during indirect operations, but a local deviation is allowed, controlling only the final effect $[1,3]$. 


\section{Technological problems when cold stamping of heavily loaded automotive elements}

The subject of the research was a bumper beam formed in the cold process by means of a rigid stamp and rigid matrix without downforce, the so-called crashforming method (fig. 2). When designing a beam tool, its geometry evolved significantly three times to fit within the imposed tolerance. These changes were necessary because of the strategic importance of parts in the event of a frontal collision of the vehicle. They resulted from the lack of sufficient rigidity of the element during crash tests. Unfortunately, the new geometry was conducive to the formation of a springback of more than $2.8 \mathrm{~mm}$ (fig. 1) and high tendency to fold material [2]. For these reasons, it was necessary to carry out a lot of cold compression analysis with a particular emphasis on the springback problem. In theoretical studies, several material models were proposed, and over a dozen numerical tests were carried out to evaluate springback with the highest value exceeding $7 \mathrm{~mm}$ (fig. 2).
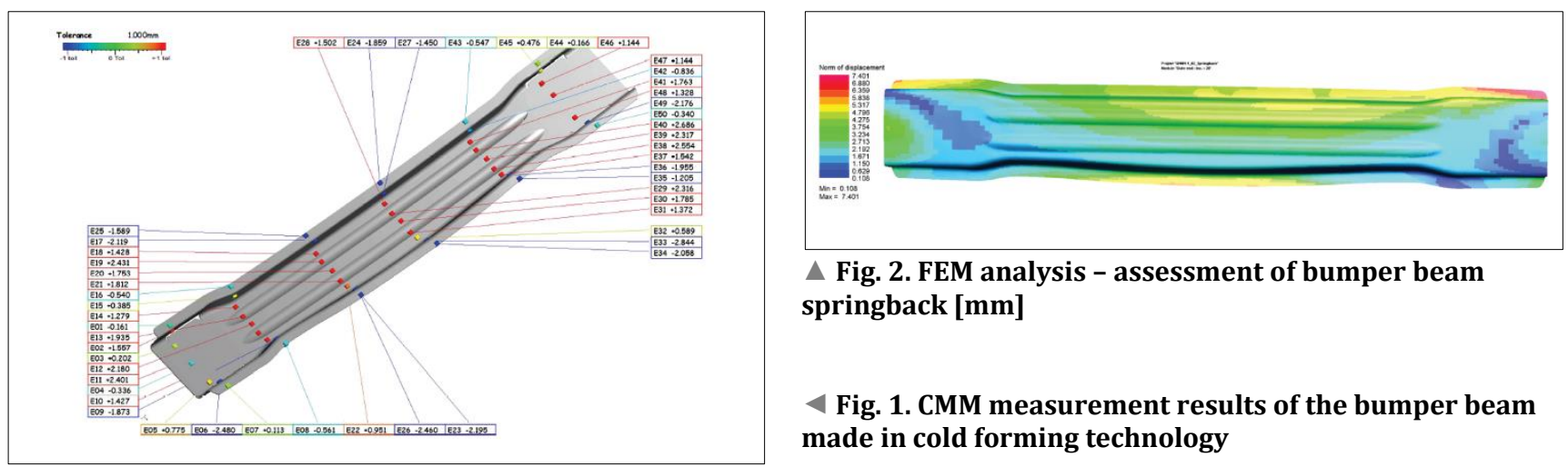

$\triangle$ Fig. 2. FEM analysis - assessment of bumper beam springback $[\mathrm{mm}]$

$<$ Fig. 1. CMM measurement results of the bumper beam made in cold forming technology

The need to maintain geometric tolerances of critical components of motor vehicles requires the use of technology to meet these requirements. Hot stamping technology gives such possibilities. It is increasingly used by car parts manufacturers to manufacture load-bearing structure elements for cars that are part of the so-called vehicle safety cages. These are car body supporting elements, such as: side pillars, bumpers, roof reinforcements, floors, doors, longitudinal beams, door frames, door sills and front walls [4].

Most car body parts are made of steel with a strength $R_{\mathrm{m}}=700 \div 1400 \mathrm{MPa}$, while steels for hot stamping allow for obtaining strength of $R_{\mathrm{m}}=1500 \div 2200 \mathrm{MPa}$. To reduce the weight of the body structure, while meeting the requirements of improving the passenger safety in the event of a collision, car manufacturers use thinner elements, but made of very high strength materials.

Hot stamped parts achieve the required strength due to simultaneous hardening (fig. 4). Steels with such high strength cannot always be cold pressed, because they usually have low elongation rate, and when pressed, they break, preventing the desired shape from being achieved.

To obtain the right geometry of the product from materials of increased strength, previously cut feeds are heated to a temperature of about $900^{\circ} \mathrm{C}$, and then - after inserting into the tool and pressing - they are cooled very quickly to a temperature of $140-150^{\circ} \mathrm{C}$ (fig. 3).

High strength is obtained if the cooling speed is kept to a minimum of $27^{\circ} \mathrm{C}$ per second, and the coolant must not come into direct contact with the part. This is achieved by a special design of the pressing tools with a network of cooling channels evenly distributed in relation to the shape of the parts and as close as possible to the shaping surface, through which the cooling fluid flows under a given pressure.

The process of heating the parts and time of heating them in the furnace until obtaining the austenitic structure, must be strictly controlled using special sensors and thermal imaging cameras that record the actual temperature of parts just before closing the tool and after opening it. Only accurate compliance with the temperature regime and times of individual stages of the process guarantees the correct strength parameters of the part produced. Any temperature deviation detected by cameras results in rejection of the part as scrap.

To prevent from oxidation of the surface of the part at such a high temperature, protections are applied by coating the sheet with special aluminum-silicon coatings or a protective atmosphere of inert gases is introduced into the furnace. Design of the tools must guarantee the correct shape of parts after cooling, i.e. they must provide for coefficients of elongation and shrinkage when pressing hot preparation and then during its rapid cooling (min. 1\%). Before thermoplastic machining, the material has a ferritic-perlite structure, while after machining - definitely martensitic. Thus, as a result of the hot forming process, the mechanical properties of the feed material change [6]. 


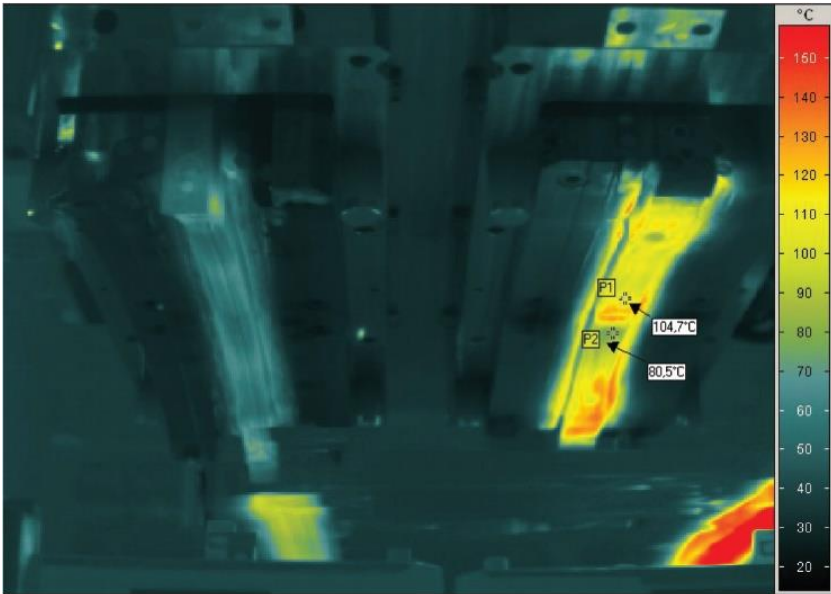

Fig. 3. Analysis of temperature distribution in a hot pressed element using thermovision

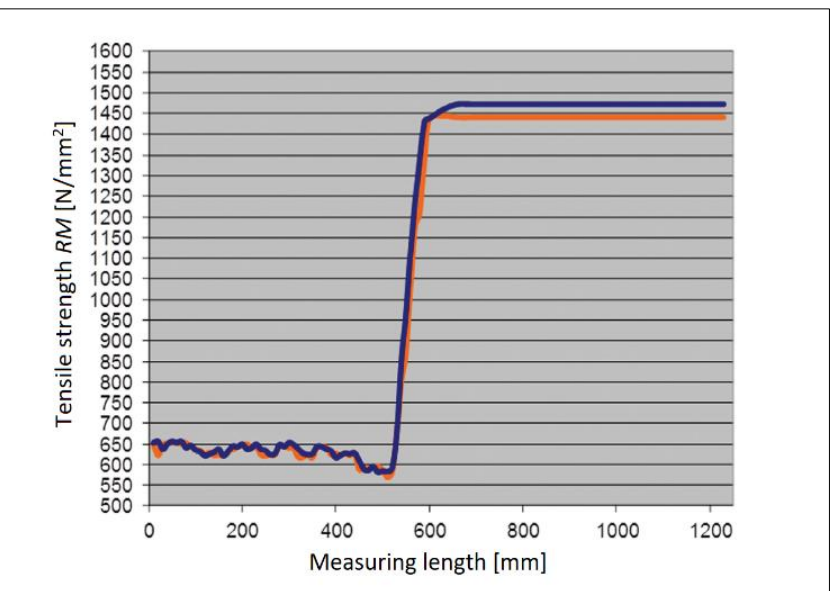

Fig. 4. Graph of tensile strength distribution as a function of measuring length for steel in hot forming technology

Hot stamping process should be designed in such a way that the final stamping has no defects in the form of cracks or folds and is made with the right shape and dimension accuracy (similar to cold stamping) and additionally has the required mechanical properties, i.e. appropriate values of $R_{\mathrm{e}}, R_{\mathrm{m}}$ and hardness as well as martensitic structure. An important element of the hot pressing process is microscopic examination, which illustrates how much percentage of martensite was formed during hardening, and the hardness to which the extrusion $(\mathrm{HV})$ has hardened.

To meet these requirements, to properly plan the hot stamping technological process and to determine its key parameters, it is necessary to perform a FEM numerical analysis of the entire process, taking into account material parameters for both plastic processing and heat machining [8].

A typical element of a passenger car structure, produced by hot stamping, is the front bumper beam. In the example under consideration, the bumper beam was made of sheet metal $1.6 \mathrm{~mm}$ thick, 22MnB5 boron steel with a strength limit of $R_{\mathrm{m}} \approx 650 \mathrm{MPa}[7,9]$.

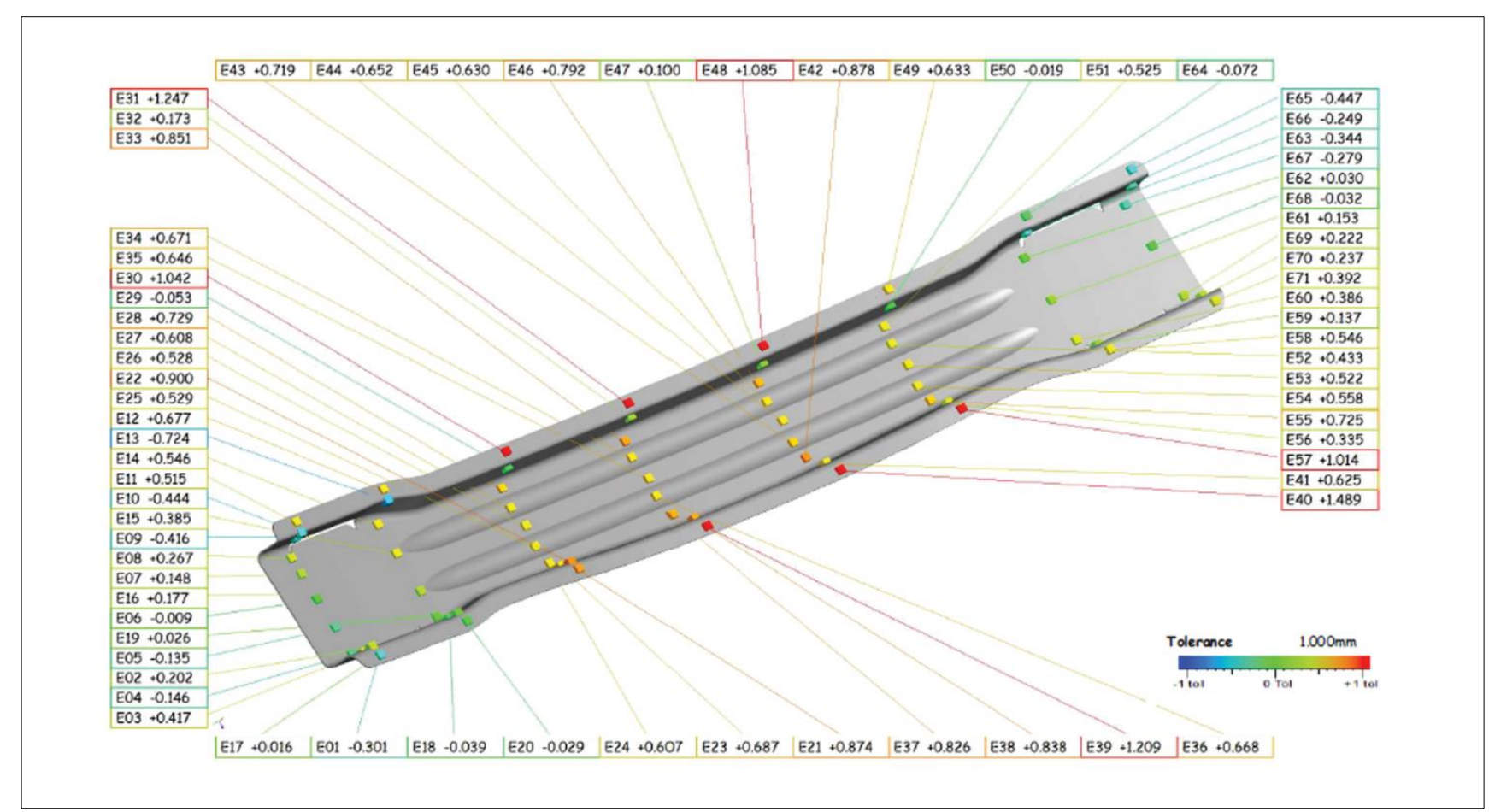

Fig. 5. Result of the bumper beam measurement made in hot forming technology

The bumper beam shaping process was carried out in the following order: first, the upper clamp closed the feed in the matrix, then the stamp closed with the feed on the lower clamp and together with the lower clamp, it closed on the stamp for $15 \mathrm{~s}$. After performing this operation, after lifting the press slider, the part extruded at $150^{\circ} \mathrm{C}$ has been spring-unloaded by a maximum value of $1.45 \mathrm{~mm}$, as measured on the CMM (fig. 5). 
The bumper beam was pressed for such modeled hot stamping process. The dimensional-shape assessment was carried out by measuring the obtained product on a CMM measuring machine, and the measurement results are shown in fig. 5. Maximum springback reached the value of $1.247 \mathrm{~mm}$, which is comparable with results obtained in the simulation process. This value is much lower than that obtained for a cold pressed product.

\section{Conclusions}

Designing and manufacturing parts resulting from hot forming technological processes is complicated, because technical factors related to plastic working and heat machining must be taken into account [5]. FEM analysis programs are useful in the comprehensive approach to cold and hot process design. They allow for checking the extrudability of the extrusion and analyzing the results of the process method simulation.

The work summarizes two methods of forming - cold and hot - which gave different results of springback. Springback of the part resulting from hot forming results in much lower displacement values. Only a few points on the edge of the part reached values close to the maximum tolerance, i.e. $\pm 1.5 \mathrm{~mm}$. CMM measurements have shown that the cold-formed part has approximately $65 \%$ of the surface outside the tolerance limit.

It should be recognized that the hot molding method minimizes the springback effect and allows for the production of high strength parts. However, it requires the use of a complex tool and technological equipment as well as the infrastructure necessary to manufacture the parts, and thus - increases the time and cost of manufacturing the car construction elements.

\section{REFERENCES}

[1] Bałon P., Świątoniowski A., Szostak J. "Improved method of springback compensation in metal forming analysis". Strength of Materials. 48, 4 (2016): 540-550, https://doi.org/10.1007/s11223-016-9796-6.

[2] Troive L., Bałon P., Świątoniowski A., Mueller T., Kiełbasa B. "Springback compensation for a vehicle's steel body panel". International Journal of Computer Integrated Manufacturing. 31, 2 (2018): 152-163, https://doi.org/10.1080/0951192X.2017.1379096.

[3] Bałon P., Świątoniowski A. "Springback compensation in cold forming process for high strength steel". Archives of Metallurgy and Materials Science. ISSN 1733-3490. 60, 4 (2015): 2471-2478.

[4] Bałon P., Świątoniowski A., Kiełbasa B., Szostak J. "Springback compensation for a vehicle's steel body panel". Proceedings of the 20th International ESAFORM Conference of Material Forming (2017).

[5] Karbasian H., Tekkaya A.E. "A review on hot stamping". Journal of Materials Processing Technology (2010) https://doi.org/10.1016/i.jmatprotec.2010.07.019.

[6] Erhardt R., Böke J. "Industrial application of hot forming press simulation". 1' International Conference on Hot Sheet Metal Forming of High-Performance Steel. Kassel, Germany (2008).

[7] Junying M., Jianping L., Jiayue L., Wenhua Bao B. "Investigation on hot forming limits of high strength steel 22MnB5". Computational Materials Science (2010): 326-332, https://doi.org/10.1016/i.commatsci.2010.05.018.

[8] Neugebauer R., Schieck F., Polster S., Mosel A., Rautenstrauch A., Schoenherr J., Pierschel N. "Press hardening - An innovative and challenging technology". Archives of Civil and Mechanical Engineering (2012): 113-118, https://doi.org/10.1016/i.acme.2012.04.013.

[9] Rong Shean L., Yi Kai L., Chien T. "Experimental and theoretical studies on formability of $22 \mathrm{MnB5}$ at elevated temperatures by Gleeble simulator". 11 th International Conference on Technology of Plasticity. ICTP. Procedia Engineering. 81 (2014): 1682-1688, https://doi.org/10.1016/i.proeng.2014.10.213. 